\title{
Method and Measurement in Sociology, Fifty Years On
}

Robin James Smith and Paul Atkinson

Cardiff School of Social Sciences

\section{Introduction}

Marking its fiftieth anniversary, we revisit Aaron Cicourel's Method and Measurement in Sociology (MM) (Cicourel 1964). In so doing we consider the book's legacy and influence in the context of the continued and urgent significance of such properly methodological inquiry. We point out that MM anticipates a good many methodological issues at the heart of contemporary debates within the social sciences and suggest that many of the issues that concerned Cicourel, far from abating, have been exacerbated. Problems of method and measurement remain pressing, not least in social scientists' responsibilities for the use and interpretation of data (cf. Savage and Burrows, 2007). In returning to key questions of methodological procedure, and of the accomplishment of 'measurement' in human affairs, we see that the frustrations of Cicourel and those who influenced him still prevail. Cicourel's critique of sociological measurement of some fifty years ago has repercussions for social researchers - of qualitative, quantitative and mixed persuasions - today. A thoroughly sociological understanding of method and measurement - as a situated, contingent, contextual and ultimately and unavoidably practical accomplishment - has a critical contribution to make within social inquiry. We also note how such methodographical work (cf. Greiffenhagen et al, 2011) is central to realising sociology's contribution and intervention as it bears on ubiquitous regimes of institutional performance measurement, league tables, risk assessments, audit, forms of digital 'big data' and indeed the whole machinery of social measurement driving a ubiquitous audit culture. Method and measurement, or rather the practices and principles of members making decisions as to what to measure and how, are powerful in producing the very contours of reality for the constitution of institutions, publics, and populations. We therefore commend a critical and empirical engagement with method and measurement as a means of addressing the ways in which measurement practices come to give 'official imprint to reality' (Goffman, 1983: 17). We begin with a review of the thrust of the critique presented in MM.

\section{The Principles of Measurement}


Although it has rather disappeared from view in current methodological texts, at one time MM was one of the most cited methodological texts in sociology, and appeared on very many reading lists for courses in research methods. Like many an influential book, MM has probably been cited and invoked more frequently than it has actually been read. Classic works often have a sort of virtual existence, constructed through imperfect memories and the uncritical use of secondary sources. Re-reading nearly always recuperates original intentions that have been obscured by succeeding simplifications and distortions. This is certainly the case with MM. Here we outline some of the key principles and critiques of measurement strategies that underpin this important text and the subsequent discussions of specific methods it contains.

A central issue tackled by Cicourel is that standard sociological procedures do not begin with, nor are grounded by, an adequate theory of (the relations of) action, meaning and interpretation. The practice of professional sociology lacks a sufficiently sophisticated understanding of its own mechanisms of causality that are the stock-in-trade for the majority of what Harold Garfinkel (2002), one of Cicourel's teachers, would come to call formal analytic sociology. This, as Cicourel has it, routinely results in sociological measurements being made by fiat. In a good deal of sociological work, one finds the imposition of categories and the reification of indicators and variables on the basis of unexamined assumptions about the phenomenon in question, and about the status and accomplishment of documents of that phenomenon in the first instance. It may often be a matter of using whatever proxy measures are available to professional social science, rather than seeking to provide a thorough examination of the phenomenon in question, or - worse still perhaps falling back on introspective subjective interpretations and individualised notions of meaning. Cicourel thus argued for an empirical attention to how the 'working theories' of researchers are operationalised in producing, handling and interpreting different forms of data. This work is itself grounded in and developed from analysts' everyday interactional competencies as described in recent methodographical work (cf. Greiffenhagen et al, 2011; Housley and Smith, 2011). In MM, Cicourel thus develops a position, owing much to the lectures and writings of Alfred Schütz (e.g. 1953; 1954), which aims to address the very grounds from which empirical inquiries proceed. Social studies of social phenomena must, then, finds ways to adequately handle the production of their available phenomena in the first instance, thus preserving their properly social character. As Schütz (1954: 261) wrote: 
All forms of naturalism and logical empiricism simply take for granted this social reality, which is the proper object of the social sciences. Intersubjectivity, interaction, intercommunication, and language are simply presupposed as the unclarified foundation of these theories. They assume, as it were, that the social scientist has already solved his fundamental problem, before scientific inquiry starts.

This strongly phenomenological and proto-ethnomethodological (Lynch, 1991) approach of $\mathrm{MM}$ is often lost in secondary accounts and subsequent receptions. Indeed, a review of such texts might lead one to suspect that Cicourel's original work consisted simultaneously of a radical critique of the quantitative research strategies that dominated sociology at the time, and a simple celebration of qualitative methods, championing qualitative research over positivist techniques, the sample survey and the use of official statistics, in particular. It should already be clear that the position developed in MM is not reducible to a naïve distinction or valuation of qualitative of quantitative strategies. Such gross simplifications obscures the book's central methodological contribution. As Cicourel explained in an interview (Witzel and Mey, 2004: 30):

Learning about mathematical statistics within mathematics is necessary in order to understand what possible alternatives might exist for creating measurement systems commensurate with the phenomena that are the focus of one's research. Let me underscore the fact that I am NOT opposed to quantification or formalization or modeling, but do not want to pursue quantitative methods that are not commensurate with the research phenomena addressed.

So, in addition to insisting that methods and 'measurement systems' are commensurate with the phenomena under consideration (a claim routinely made in social research, but seldom examined), MM aims to establish measurement as an inescapably practical and situated activity, accomplished via various methods ('ethno' and 'scientific') and in various institutional contexts ${ }^{1}$. Measurement is positioned as a decision-making process accomplished within these contexts and disciplinary and institutional frames. Cicourel identifies an exercise on coding data for his study of juvenile justice as a key exemplar in the development of his thinking in this vein. As Garfinkel (1967) later noted and had observed in

\footnotetext{
${ }^{1}$ There are, of course, mundane measurement practices too - see Crabtree et al (2013) .
} 
coders' practices in the suicide prevention centre (1997[1967]), often this process remains 'up for grabs' until the production of the final version, after which the various prior stages, trials and mistakes, best estimates and bad decisions are submerged and smoothed in a posthoc account. More specifically, the dual nature of measurement - conceptual or theoretical frames on the one hand, and practical activities on the other - is seldom made explicit in either sociological inquiries or other institutional work. Cicourel's own attention to such matters was informed by issues of coding in the context of his study of juvenile Justice (Cicourel, 1968).

Cicourel's central concern and critique developed in MM is thus double-edged. As demonstrated in his other studies in that period (Cicourel, 1963; 1968 1974), measurement is a process of decision-making, practically realised, embedded in the social conditions, situations and structures in which it is accomplished. This is often lost in contemporary treatments of 'method' as simply a neutral tool for getting a job done (that job being the straightforward measure of social reality for professional purposes). There is thus a continued significance for a properly sociological rendering of measurement for the practice of the social sciences themselves and for the contribution of sociology in analysing and critiquing measurement practices in society. Whatever the institutional context, understanding measurement as an unavoidably practical and situated activity opens it up as a topic of sociological, ethnographic and ethnomethodological inquiry. MM is a call for sociology to pursue a programme of research that levers open the black box of measurement. The practical grounds of powerful and seemingly immutable social facts are displayed.

\section{Questions of Method}

Understood within this wider project, MM is far from an uncritical endorsement of some research strategies above others. Cicourel is engaged in a thorough evaluation of the foundations of sociological knowledge. We describe here the ways in which the underlying principles of MM, outlined above, pervade the discussion of specific methods.

Notwithstanding retrospective views of MM, it is clear that Cicourel was in no sense celebrating 'qualitative' research strategies in contradistinction to surveys and the like. His comments on field research and interviewing are just as pointed as his critique of other statistical and purely numeric approaches. Cicourel has a good deal to say about the conduct 
of field research (by participant observation) and face-to-face interviewing. In rereading MM, it needs to be remembered that - in common with many of the methods Cicourel discusses there was a relatively restricted corpus of qualitative methodological literature for Cicourel to draw on. By the early 1960s there were few discussions of field research, or ethnographic research as it might more usually be called today. Equally, there was nothing like the literature reflecting on the nature and conduct of the social-science interview. Like the rest of the book, the relevant chapters focus on how everyday knowledge and background assumptions enter into the practical conduct of sociological research. What is perfectly clear is that Cicourel is no advocate of field research as a simple alternative to quantitative or more systematic procedures. Indeed, his comments on field research suggest quite severe strictures on its conventional conduct. In discussing field work and its conduct, Cicourel admits that he is proposing unrealisable ideals, and that he sets up something of a straw-man argument. He notes that there was an emergent and growing literature on key aspects of field research (such as processes of access or establishing field roles), but suggests that field researchers proceed without explicit theoretical explication of how they interpret observed social action, or indeed how that action is made available for interpretation. They therefore have but a shaky scientific warrant for their analyses. This is the (now) familiar, albeit not fully or even widely acknowledged, critique of the common-sense foundation of much sociological analysis, whether based on fieldwork or otherwise, in which 'they simply put some category in. They make sense to us in doing that, but they're doing it simply as another Member' (Sacks, 1995: 41-2). In other words, sociological analysis deals with and relies upon the same reasoning and language practices as any other activity done by people in society. This fact remains unacknowledged in approaches which treat the availability of common language as a resource for, rather than topic of, inquiry.

When he turns to the practicalities of interviewing, we find a similar perspective. Cicourel uses a small number of methodological texts on the sociological interview in order to raise some fundamental issues that have subsequently been widely rehearsed. As is the case throughout MM, the emphasis is on the researcher's unacknowledged and unexamined reliance on everyday or common-sense knowledge. The interview is a social, communicative encounter, and the interviewer must make on-the-spot interpretations in constructing the conversation, relying on the competence of ordinary conversational methods. In Cicourel's own words,

This discussion of interviewing as both method and object of social study from the theoretical orientation of this book will attempt to show how common-sense 
knowledge and everyday language and meaning enter into the role-taking process of the interview; how common-sense interpretations must be used as technical knowledge by the interviewer for deciding how the information obtained from the respondent is to be interpreted. (p. 76)

One might also add that, of course, the respondent is equally engaged in acts of interpretation in order to generate appropriate responses. Even a cursory survey of the 'most read' lists of leading methodologically focused journals demonstrate how this issue is still being grappled with; a survey of journals that comprise in the main of interview based 'qualitative research' will demonstrate that how researchers and respondents, together, 'do data' (Hester and Francis, 1994) deserves continued attention.

Just what was it that Cicourel had to say about survey research and the data derived from questionnaires? Although the chapter on questionnaires is quite short, it provides the most characteristic of his sociological critiques, and because it is memorable it is - as already suggested - associated with the radical critique of statistics. In some quarters, this is the enduring memory of MM. At the heart of the discussion is the repeated assertion that the conduct of questionnaire-based research draws upon common-sense assumptions about language and knowledge in order to construct equivalences between individual predispositions, such as 'attitudes' and 'beliefs', and standardised indicators (questionnaire items). Equally, Cicourel suggests that topics conventionally regarded as standard 'facesheet' data (age, sex, occupation) warrant a more culturally and socially sensitive treatment. The translation of 'variables' into two or more categories also seems to be arbitrary in many cases in light of the social phenomena that they purport to measure. The issues underlying these and other topics in MM are not simple matters of methodological preference. Indeed, the very notion that one method might be a priori 'better' than another is challenged by MM. Cicourel was not simply reacting against dominant ways of doing professional sociology at the time that MM was written. His critiques do not result in a simple set of methodological precepts or priorities.

As we have already seen, Cicourel's comments on measurement are by no means based on a crude assertion that social life is not 'measurable' in general, or that it does not lend itself more narrowly to quantitative forms of representation. We need to appreciate his wider perspective. And in this broader sense, we find MM alluding to the sociology of knowledge in which the methods of sociological research are themselves topics of the sociology of 
knowledge, as well as being resources in studying knowledge. To emphasise this point, there is nothing in MM that explicitly constitutes a critique of quantification per se. 'Measurement' here means something a good deal more profound than the casual, or lazy, equation of measurement with quantification. Cicourel's book is anything but lazy, and he addresses the issues primarily as topics in the sociology of knowledge. We can get a sense of the power of his critique of the sample survey. The survey was widely regarded as the method of choice for sociologists - especially in the United States - and any fundamental critique of it was readily seen as a radical assault on the foundations of disciplinary knowledge. Indeed, the import of Cicourel's commentary was as radical in its reception as the so-called crisis of representation (Marcus and Fischer, 1986) that afflicted cultural anthropology two decades later. Both critiques addressed the taken-for-granted bases of legitimacy of the disciplines.

\section{Measurement, social science and the sociology of knowledge}

In a way that is entirely characteristic of the period and its intellectual style, MM is informed by a stated desire to promote 'scientifically' adequate sociological knowledge. In particular, he explores how the contents of sociological knowledge are permeated by the language and knowledge of everyday life: 'The confounding of sociological language about sociological theories, social events, and the language used by subjects under study is a basic problem in field research and other research methods such as content analysis and laboratory experiments' (p. 2). The common language problem should also be considered in relation to sociological measurement which repeats or reflects the institutional or bureaucratic processes which produce data taken 'as given' by social scientists. In other words, the overall critique is an early version of the ethnomethodological programme, addressing the recurrent topic/resource distinction in relation to communicative practice and (the progressive flattening of) the relation between scientific and everyday knowledge. The problem, then and now, faced by the social scientist is the 'no time out' fact that they, irrevocably and unavoidably, operate within the same linguistic frames as that which constitute and categorise the object of study, the realities and organizational features of the phenomenon being analysed, measured and described. Cicourel draws on Schütz (see, in particular, pp. 60-1) to see how the 'professional' categories employed by the social scientist are forever predicated by, grounded in, and indistinguishable from the very same categories and mundane reasoning practices (Pollner, 1987) employed by members in the course of socially organised activity. It is in this sense that any form of measurement is seen as both problematic and as topic of inquiry (and see Lynch, 1991). What is needed, Cicourel asserts at the very outset, is a theory 
of instrumentation and a theory of data, so that the observer's priorities, theories and interpretative work can be disentangled, or at least distinctly acknowledged, from the materials and artefacts that are available as that observer's 'data'.

In evaluating the grounds of the construction of sociological knowledge, it is noticeable how often Cicourel invokes the yard-stick of 'science'. Here the transformation in sociology itself might be instructive. When MM was published, sociological studies of scientific knowledge were few and far between, and there was little in the mainstream of American sociology. If we now were to apply Cicourel's method - of treating sociological research as a topic in the sociology of knowledge itself - then we would have a much greater wealth of sources on the sociology of science on which to draw (e.g. Collins, 1992; Lynch et al, 1983; Merton, 1973; Latour, 1987). In doing so, we might be willing to suspend cherished assumptions concerning 'science' itself. We would be forced to recognise that there is no scientific knowledge 'natural' or otherwise - that is not itself informed by everyday practices, local judgments and acts of classification. We might be forced to acknowledge in turn that the objects of science are as thoroughly constructed as the objects of sociological knowledge. A twenty-firstcentury version of MM would have to acknowledge that the benchmark of 'science' is itself a rhetorical construction, while appeals to science themselves often rest on questionable assumptions about what constitutes valid knowledge (not to mention debates relating to the (im)possibility of demonstrating causality in social studies (Winch, 1958)). In that sense, MM may now seem crude in its invocations of science. Scientific and social-scientific knowledge would now be subjected to critical scrutiny in a symmetrical manner, while science would not be invoked as a gold standard. It does, however, remain apt in it strictures on particular sociological techniques.

\section{The sociology of measurement}

Sensitivity to measurement - coding decisions especially - has become especially pressing with the rise of 'audit culture' in and across many contexts. The assessment of performance, the compilation of league tables, and the punishment of under-performance have meant that measurement has achieved an ever-more significant role in the political economy of welfare, education, administration and business. The use of management information, much of it based on the routine collection of statistics, is dependent on the development, production and interpretation of standardised measures, often collected repeatedly at regular intervals and 
used to track relative, institutionally defined, success and failure. They are often used to make direct comparisons between agencies and organisations at all societal levels - from nationstates down to individual schools, hospitals or welfare agencies. Individuals and organisations are also measured against 'key performance indicators', serving similar functions, comparing standardised outcomes against predetermined criteria of success often produced from generic principles from at (at least) one step remove from the practice they are intended to assess.

It is abundantly clear that the statistics themselves (as opposed to the political decisions based on them) are contentious. The idea that there is a 'story behind the stats' is commonplace, the awareness that this might include their very practical production far less so. Crude comparisons and interpretations are often placed on numerical data that are in turn based upon a host of assumptions and measurements that are predicated on classifications and codings that are in turn reliant upon human judgment and the actual business of producing an maintaining material records; statistics and their uses are pervaded by practical and technical issues of data and their interpretation. The contentiousness of their use does not lie simply in the political and administrative decisions based on them. Decisions involved in the accomplishment of the measurement practices are just as political as the decisions made with those measurements.

Of course, it is not only statistical and quantitative approaches that are found in within wider social and institutional contexts. The interview is also an increasingly pervasive form of assessing and measuring. Aligned with the reification of the individual within social sciences and a Romantic understanding of the self and subjectivity, interviews are regularly employed to 'discover' what someone really thinks or feels (Atkinson and Silverman, 1997; Baker, 2002). These assertions and applications of the interview are as problematic as the unquestioning use of statistics as reflecting social reality. In a way similar to, but going beyond, the production and interpretation of statistics, the conduct of the interview is thoroughly context-dependent. That context includes local cultural knowledge that informs the interviewer and the respondent, the setting of the interview, and the ethnomethods available to the participants in producing the interaction as an interview. We have had a great deal of methodological commentary on the interview, and the observation that it is a situated encounter, in which the exchange of talk is locally produced, no longer sounds quite as radical as it might have done at one time. But when Cicourel first published his 
methodographic studies, he seemed to be striking at foundations. Nevertheless, the extended interview is a taken-for-granted mode of social inquiry that is far too frequently used in an uncritical, unreflective way and with insufficient regard for its actual accomplishment as a social encounter.

Cicourel pursued these concerns in further empirical and methodographical work. In Theory and Method in a Study of Argentine Fertility, Cicourel (1974) examines the role of theory and method for and within a study of fertility and reproductive behaviour. Although there are introductory chapters by way of background, and some descriptive 'ethnographic' writing on the social setting, the main contribution lies in the discussion of the accomplishment of interviews as employed in the study. Cicourel devotes himself to an extended consideration of how the interviews conducted with Argentinian couples were actually enacted and how they unfolded through and in relation to the interviewer's in situ interpretations and questioning strategies. As is more readily recognised now, the import of questions and answers reflect what has gone before in the course of the interview and thus significance, meaning and intent develop in stepwise, sequential, fashion. As we would expect, given Cicourel's methodological interests, he focuses on the interpretative procedures whereby series of spoken exchanges might be condensed into standard ('appropriate') responses. Cicourel also includes a discussion of the problems of coding responses to open-ended questions. In has become a familiar style, he uses a number of concrete examples from the study to display how a coder might need to invoke general cultural knowledge as well as familiarity with the unfolding interview itself in order to make 'reasonable' inferences about the respondent's intentions, thus raising the issue of ecological validity in a manner that is available for empirical inspection. The standardised 'variables' that might be also understood as antecedents or determinants of fertility are thus shown to be the product of interpretative work. In his work on educational decision-making (with Kitsuse, 1963), Cicourel had dealt with the pervasive practices of educational measurement and the assessment of educational ability. The high-school ethnography demonstrates how ad hoc judgments of aptitude had real and lasting (and hence self-fulfilling) effects on the students and their educational careers. In the same vein, the monograph on juvenile justice (Cicourel, 1968) documents the practical, interpretative work that goes into the construction of types, categories and outcomes. Hence the statistical rates of educational attainment and of juvenile offending are shown to be based on processes of interpretation and inference that inscribe ad hoc judgements. Processes of classification (the 'social construction' of categories) are 
mechanisms of measurement. Studies of diagnostic inference in medicine are therefore key aspects of a generic sociology of measurement. Bowker and Starr's (2000) analysis of diagnostic categories, such as those enshrined in the Diagnostic and Statistical Manual is a major contribution to the sociology of measurement in its own right and is in direct line of descent from Cicourel.

\section{Contemporary contestations of measurement practices}

The United Kingdom has witnessed many examples in recent years, but the most recent controversy in health care illustrates the point. A unit performing cardiac surgery for children was closed following the publication of numerical data purporting to show unacceptably high death-rates. This followed an investigation into an English hospital trust that also showed highly standardised mortality rates. Both were treated as scandals in the mass media, accompanied by reports of numerous 'excess' deaths as a result of poor care or failed surgery. Now it is clear that there is no simple enumeration possible of 'mortality'. Rates of death in hospital have to be standardised in terms of the demographic characteristics of patients and the attendant risks, the severity of the conditions treated, the nature of surgery and other treatments, and so on. The methods used to achieve such standardisation are themselves open to dispute. But before such statistical work can be done, medical conditions, treatments and outcomes all have to be enumerated. Therefore they all have to be coded. There are international classifications of diagnostic and treatment categories which remain inextricably dependent on the judgment of coders, working with data that are themselves, in the first instance, dependent on medical practitioners' judgments. Measured outcomes - in terms of standardised mortality rates - depend on how medical staff list conditions and complications, and on discharge practices (e.g. to hospices for terminally ill patients). In other words, apparently simple decisions - the support or closure of clinical services - depend entirely on chains of local practices, professional judgments, classificatory decisions, and coding accuracy. These chains of interpretive practice are then transformed into statistics that are frequently reported and acted upon with little explicit acknowledgement by policy-makers and politicians of sampling issues, distributions, significance levels, outliers, standard errors; indeed the entire spectrum of statistical inference is often elided from the decision-making process.

To take an example from another institutional domain, league tables have become a common and taken-for-granted feature of contemporary public life. Like hospitals, schools colleges and universities are all ranked according to a variety of measures. All such league 
tables have a number of features that deserve critical attention. First, there is a presentational issue: league tables often exaggerate difference. Once ratio-level measurements are turned into a single ordinal-level ranking, then tiny differences in absolute scores can be turned into what look like major differences in performance and reputation. Moreover, the choice of indicators often seems to be based on the numerical data available rather than a principled assessment of what data ought to be gathered. Then again, the combination of a series of indicators into a single scale is dubious at best. It is far from clear that student-staff ratios, the number of international staff and the number of citations to publications (for example) can really be combined into a single score of excellence. It is even less clear that the number of first and upper-second-class degrees awarded is a single measure of anything: in some contexts it may reflect the excellence of the student-intake, in others the excellence of the teaching, and in yet others the very low standards applied by examiners! It is clear that even on the basis of the data available, a multi-dimensional analysis would be more faithful. But of course that would undermine the league-table ordering that is the desired effect.

It is abundantly clear that we have a continuing and urgent need for programmes of research on the social production, presentation and interpretation of a vast range of measurement in public life. Research programmes such as Evelyn Ruppert's multi-site investigation of European statistics is one key exemplar of the kind of research that is needed across a wide range of agencies and kinds of data. It also exemplifies how social scientists need to synthesise quantitative and qualitative research expertise. Indeed, we need rigorous qualitative studies of a wide range of emergent measurements and experimental methods. We especially need careful examinations of those procedures that are widely regarded as the gold-standard benchmarks of methodological procedure. For instance, as Berg and Timmermans (2010) have demonstrated, close sociological investigation reveals that 'gold standard' methods rest on shaky foundations. Ethnographic studies of RCTs in medical research suggest that their status can be open to question. Clinicians' equipoise between different treatments can be difficult to sustain. The enrolment of patients into clinical trials rests on chains of diagnostic inferences that are extrinsic to the research design itself (e.g. the staging of a tumour), and may be susceptible to normal (Type I or Type II) error. This is far more than a matter of critique, and it goes beyond improving the validity of statistics and classifications. A sociology of measurement - conceived as a branch of the sociology of knowledge - is one goal. It thus has close affinities with the sociology of scientific knowledge. As we have already suggested, the two are inextricably linked. 


\section{Conclusion}

In revisiting the classic Method and Measurement, and outlining its legacy and influence, we aimed to achieve something worthwhile in celebrating this book per se and in pointing to the continued significance of approaching measurement as a practical decision-making activity. As we noted, this contribution is double-edged. Cicourel's strictures on sociological research that is not attentive to its own sociology of knowledge remain valuable. They provide valuable correctives to a variety of extreme positions, not least -as we have suggested various forms of 'interpretative' and 'qualitative' research that lack theoretical and methodological rigour. They also provide correctives to ill-conceived forms of measurement, in which inappropriate or unduly crude categories are imposed more or less arbitrarily, without due regard for the forms and contents of socially organized everyday life and knowledge. There is, thus, significance for the sociological questioning and examination of the practices of social science, not for purpose of gleefully tedious introspection, but as a means of keeping a rigorous sociological imagination alive and relevant ${ }^{2}$.

$\mathrm{MM}$ also endorses an empirical programme in the sociology of knowledge and measurement informed by the systematic study of the sociology of categorisation practices. In this sense, we aimed to demonstrate that MM can serve as a continued source of instruction and inspiration for sociologists aiming to examine the ways in which measurement gets done in a range of other professional and institutional fields and settings. As we have briefly outlined above, measurement is becoming increasingly central to the constitution of contemporary subjectivities, identities and experiences; there is much work for sociologists - and ethnographers and ethnomethodologists in particular - to do in relation to the ways in which populations, publics and selves are made up in and through increasingly pervasive measurement strategies. From decisions made in local educational settings to global economics, measurement is a constituent feature of the ways in which the present and future are configured yet remains an unavoidably practical and situated activity. Such areas of inquiry are, we trust, interesting enough sui generis; as fields of human activity, just like any other. We suggest, moreover, that sociology has a particular warrant for the description of the practices in and through which the official contours of social reality are shaped and a responsibility to ensure its own means and modes of inquiry are fit for this purpose. A warrant and responsibility for which MM can still be foundational.

\footnotetext{
${ }^{2}$ See http://sociologicalimagination.org/archives/16120 for Howard Becker, interviewed by Les Back, speaking on this and other topics.
} 


\section{References}

Atkinson, P., \& Silverman, D. (1997). Kundera's Immortality: The interview society and the invention of the self. Qualitative Inquiry, 3(3), 304-325.

Baker CD (2001) Ethnomethodological analysis of interviews. In: Gubrium JF and Holstein JA (eds.) Handbook of Interview Research. pp. 777-796 London: Sage

Bowker, G. C., \& Star, S. L. (2000). Sorting things out: Classification and its consequences. MIT press.

Cicourel, A. V. (1964) Method and Measurement in Sociology. New York: The Free Press.

Cicourel, A. V. (1968) The Social Organization of Juvenile Justice. New York: Wiley.

Cicourel A.V. (1974) Theory and Method in a Study of Argentine Fertility. New York: John Wiley and Sons.

Cicourel, A. V., \& Kitsuse, J. I. (1963) The Educational Decision-Makers. Indianapolis: Bobbs-Merrill.

Collins, H. M. (1992) Changing order: Replication and Induction in Scientific Practice. London: Sage.

Crabtree, A., Tolmie, P., and Rouncefield, M. (2013) "Cooking for Pleasure" in P. Tolmie and M. Rouncefield (eds.) Ethnomethodology at Play pp. 21-52 Farnham: Ashgate

Garfinkel, H. (1997[1967]) 'Practical sociological reasoning: some features in the work of the Los Angeles Suicide Prevention Center' in M. Travers \& J. F. Manzo, (eds.) Law in Action: Ethnomethodological \& Conversation Analytic Approaches to Law. Aldershot, UK: Dartmouth Publishing Co.: 25-41

Garfinkel, H. (2002) Ethnomethodology's Programme: Working out Durkheim's Aphorism (ed. Anne W. Rawls). Maryland: Rowman and Littlefield Publishers Inc

Goffman, E. (1983) The Interaction Order: American Sociological Association, 1982 Presidential Address. American Sociological Review. (48)1: 1-17

Goldstein, H. (2014) Using league table rankings in public policy formation: statistical issues, Annual Review of Statistics and its Applications. 1: 385-400.

Goldstein, H. (2004). International comparisons of student attainment: some issues arising from the PISA study. Assessment in Education: principles, policy \& practice. 11(3): 319-330 
Greiffenhagen, C., Mair, M., Sharrock, W. (2011) From Methodology to Methodography: A Study of Qualitative and Quantitative Reasoning in Practice Methodological Innovations Online. 6(3): 93-107

Hester, Stephen, and David Francis. (1994) Doing data: the local organization of a sociological interview, British Journal of Sociology. 45(4): 675-695.

Housley, W., \& Smith, R. J. (2011). Telling the CAQDAS code: Membership categorization and the accomplishment of 'coding rules' in research team talk. Discourse Studies. 13(4): 417-434

Latour, B. (1987) Science in Action. Cambridge, MA: Harvard University Press

Lynch, M., Livingston, E., Garfinkel, H. (1983) 'Temporal order in laboratory life' in K.D. KnorrCetina \& M. Mulkay (eds.) Science observed: perspectives on the social study of science. pp. 205-38 London: Sage:

Lynch, M. (1991) "Method: measurement - ordinary and scientific measurement as ethnomethodological phenomena" in G. Button (ed.) Ethnomethodology and the Human Sciences. pp. 77-108 Cambridge: Cambridge University Press

Marcus, G., \& Fischer, M. (1986) Anthropology as cultural critique: An experimental moment in the human sciences. Chicago: University of Chicago Press

Merton, R. K. (1973) The Sociology of Science. chicago: University of Chicago Press

Pollner, Melvin (1987) Mundane reason: reality in everyday life and sociological discourse. Cambridge: Cambridge University Press

Savage, M., \& Burrows, R. (2007). The coming crisis of empirical sociology. Sociology. 41(5): 885-899.

Sacks, H. (1995) Lectures on Conversation (vol.1, ed. G. Jefferson). Oxford: Blackwell Publishers Ltd.

Timmermans, S., \& Berg, M. (2010). The gold standard: The challenge of evidence-based medicine and standardization in health care. Philadelphia: Temple University Press.

Turner, D. (2005) Benchmarking in universities: league tables revisited, Oxford Review of Education, 31, 3: 353-371.

Witzel, Andreas \& Mey, Günter (2004). "I am NOT Opposed to Quantification or Formalization or Modeling, But Do Not Want to Pursue Quantitative Methods That Are Not Commensurate With the Research Phenomena Addressed." Forum Qualitative Sozialforschung 5(3): 41, http://nbn-resolving.de/urn:nbn:de:0114fqs0403412. 
Winch, P. (1958) The Idea of a Social Science and its Relation to Philosophy London:

Routledge 